\title{
Suspension Polymerization of Styrene Using Zinc Oxide as a Suspension Agent
}

\author{
Rochmadi and Edy Widjaja \\ Department of Chemical Engineering, Faculty of Engineering, Gadjah Mada University, Yogyakarta 55284, Indonesia
}

Received: April 30, 2011 / Accepted: May 12, 2011 / Published: September 25, 2011.

\begin{abstract}
The advantage of suspension polymerization is that the polymer product can be separated easily from the mixture of reaction product, in the form of small spherical polymer solid. This method is commonly employed in the production of expanded polystyrene. This research has investigated the reaction rate of suspension polymerization of styrene, along with the product characteristics. Classical model on chain polymerization was proposed, to determine the rate of reaction. The experiment was conducted in a three neck flask provided with a stirrer and water bath. The reaction was run at temperature $60{ }^{\circ} \mathrm{C}-90{ }^{\circ} \mathrm{C}$ and $\mathrm{pH}$ of 10 . Sample was taken regularly from the reaction mixture at certain time, and the remaining styrene monomer in the sample was determined by gravimetric method (i.e. vacuumed vaporization). In the end of experiment, the polymer product (in the form of small sphere) was separated from the suspension mixture, dried and measured its diameter. The molecular weight of polystyrene product was measured by capillary viscometer. The results showed that the proposed reaction rate model fitted well to the experimental data, with its relative error being around $2.38 \%-10.9 \%$, hence it was good enough to describe suspension polymerization process. The overall polymerization reaction rate constants was around 2.34-45.1 (L/mol $)^{0.5}$, which depends on mainly the reaction temperature. The initiator decomposition rate constant was around 0.0051-0.0091 $\mathrm{min}^{-1}$. Suspension agent concentration did not influence the styrene conversion. The diameter of polystyrene particle was around 0.1-1 $\mathrm{mm}$, which was influenced by reaction temperature and suspension agent concentration. Viscosity average molecular weight of polystyrene products was between 100,000 to 670,000 .
\end{abstract}

Key words: Suspension polymerization, styrene, zinc oxide, suspension agent.

\section{Nomenclature}

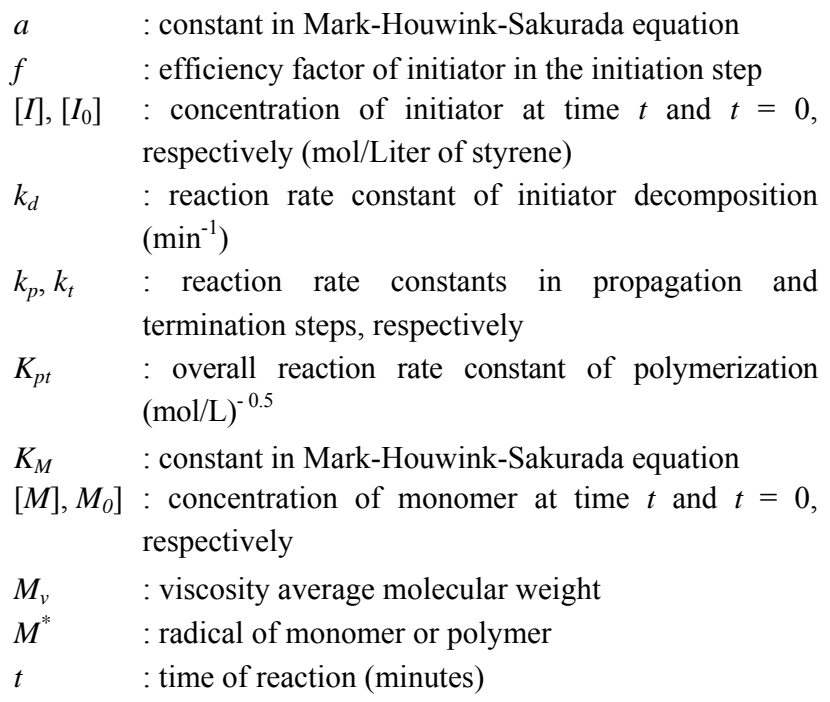

Corresponding author: Rochmadi, professor, research field: polymer synthesis, modelling. E-mail: rochmadi@ chemeng.ugm.ac.id. $x \quad$ : monomer conversion

\section{Greek letters}

[ๆ] : intrinsic viscosity $(\mathrm{g} / \mathrm{dL})$

\section{Introduction}

Polystyrene (PS) is one of the big four of synthetic polymer used in the world, besides polyethylene (PE), polypropylene (PP) and polyvinyl chloride (PVC). Various PS applications is commonly encountered in modern life, such as electronic casing, packaging, insulators. Polystyrene is commercially produced by bulk and suspension processes. Polymerization of styrene is generally carried out in radical mechanism, i.e., using initiator, although for specific purposes, the polymerization is carried out in ionic polymerization. One of the interesting processes of PS production is suspension polymerization, because the polymer 
product can be separated and purified easily. Suspension polymerization is carried out by stirring monomer liquid in water, with the addition of initiator and suspension agent. Stirring effect produces dispersion of small monomer droplets in water phase, in which the initiator dissolves much more in monomer phase than in the water phase. Consequently, polymerization only takes places in the monomer droplet. The role of suspension agent is to prevent droplet coalescence during polymerization process. Suspension agent does not dissolve in monomer droplet, but attaches at the droplet interface. Suspension polymerization of styrene produces small spherical particle of PS, imitating pearl or bead. Expanded polystyrene (EPS) is made of spherical particle of PS, by soaking the particle in butane or pentane (as blowing agent). The rate of styrene suspension polymerization in commercial process as well as particle size is generally unavailable. This data is however very important for the design of styrene polymerization reactor. The purpose of this research is to investigate the rate of styrene suspension polymerization and the particle size of PS product, in the laboratory stage.

The design of cylindrical reactor for suspension polymerization has been investigated [1]. They discussed on the practical aspects of laboratory scale suspension polymerisation such as the choice of stabiliser, polymerisation conditions, and particle size. Hollow gelular beads of styrene-divinylbenzene copolymer have been prepared by controlling the polymerization temperature and the amount of initiator [2]. They described the mechanism for the formation of hollow beads. Researches on seeded suspension polymerization have been carried out to obtain big particle diameters [3], including modeling and optimization [4]. Modified suspension polymerization of styrene-divinylbenzene in the presence of toluene, cyclohexanol and heptane as porogenic diluents have been studied [5]. This was used for the slow release carrier of actives in cosmetics or pharmaceuticals.
Investigation of the particle size distribution of suspension polymerisation of styrene in an agitated vessel has been conducted [6]. Theoretical study on suspension polymerization has been conducted [7,8]. Particle size distribution was predicted by CFD. Lewin has modelled industrial PVC suspension polymerization reactor as well as its control. Measurement of particle size distribution in suspension polymerization using in situ laser backscattering has been conducted [9]. The effect of dispersed phase viscosity upon drop coalescence has been investigated [10]. Kinetic aspects of styrene minisuspension polymerization using a mixture PVA-SDS as stabilizer have been studied [11, 12].

Existing researches so far have much concerned with the formation of polymer droplet and its characteristics, but have little attention to the rate of reaction. Although this paper was based on the lab scale investigation, it is expected to have contribution to the process design of suspension polymerization area.

Suspension polymerization is basically bulk polymerization that occurs in small spherical monomer droplets. Styrene polymerization using radical initiator is essentially addition polymerization in chain reaction. The mechanism of this polymerization consists of three steps: initiation, propagation and termination [13].

In the initiation step, one initiator molecule (I) decomposes into two active radicals $\left(\mathrm{R}^{*}\right)$. This radical will react with monomer $\mathrm{M}$ to make active monomer radical $\left(\mathrm{RM}^{*}\right)$.

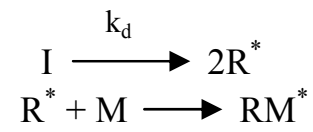

The rate of initiation reaction is simplified into:

$$
r_{i}=2 f k_{d}[I]
$$

In the propagation step, active $\mathrm{RM}^{*}$ reacts with other monomers, to form a chain of monomers or polymer radical. This reaction takes place very fast.

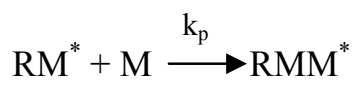




$$
\mathrm{RM}_{\mathrm{x}}^{*}+\mathrm{M} \stackrel{\mathrm{k}_{\mathrm{p}}}{\longrightarrow} \mathrm{RM}_{\mathrm{x}+1}^{*}
$$

Thousands of monomers are linked to become one polymer molecule in a fraction of second. The rate of propagation is:

$$
r_{p}=k_{p}\left[M^{*}\right][M]
$$

Two polymer radicals collide and produce one or two dead polymers in the termination step.

$$
\mathrm{RM}_{\mathrm{x}}^{*}+\mathrm{RM}_{\mathrm{y}}^{*} \mathrm{RM}_{\mathrm{x}}+\mathrm{RM}_{\mathrm{y}} \text { (disproportionation) }
$$

The rate of termination reaction is:

$$
r_{t}=2 k_{t}\left[M^{*}\right]^{2}
$$

The conservative and classical approach to develop the overall rate of polymerization reaction is to take assumption that the radical concentration is constant during the reaction. This leads to the conclusion that the rate of initiation (radical production) is equal to the rate of termination (radical depletion), or $r_{i}=r_{t}$.

This results in:

$$
\left[M^{*}\right]=k_{p}\left[\frac{f k_{d}[I]}{k_{t}}\right]^{1 / 2}
$$

Substitution of this equation into Eq. (4) produces:

$$
\begin{gathered}
\left.r_{p}=k_{p}\left[M^{*}\right] M\right]=k_{p}\left[\frac{f k_{d}[I]}{k_{t}}\right]^{1 / 2}[M] \\
-\frac{d[M]}{d t} \approx r_{p} \rightarrow-\frac{d[M]}{d t}=k_{p}\left[\frac{f k_{d}[I]}{k_{t}}\right]^{1 / 2}[M](8)
\end{gathered}
$$

In the initiation step, the rate of initiator decomposition is $[I]=[I]_{0} e^{-k_{d} t}$. Substitution of this equation into Equation (8) and followed by integration results in:

$$
-\ln \left(\frac{[M]}{\left[M_{0}\right]}\right)=2 k_{p}\left(\frac{f\left[I_{0}\right]}{k_{t} k_{d}}\right)^{0.5}\left[1-e^{-0.5 k_{d} t}\right]
$$

The use of conversion $x$, instead of $[M]$, is more suitable, because conversion is easily calculated from the experimental data. Eq. (9) is then converted into:

With

$$
-\ln (1-x)=2 k_{p}\left(\frac{f\left[I_{0}\right]}{k_{t} k_{d}}\right)^{0.5}\left[1-e^{-0.5 k_{d} t}\right]
$$

$$
K_{p t}=2 k_{p}\left(\frac{f}{k_{t} k_{d}}\right)^{0.5}
$$

$$
-\ln (1-x)=K_{p t}\left[I_{0}\right]^{0.5}\left[1-e^{-0.5 k_{d} t}\right]
$$

Eq. (10) is the proposed model of suspension polymerization reaction. Constants of reaction $K_{p t}$ (overall reaction rate) and $k_{d}$ (initiator decomposition rate) are determined by minimization of sum of square of errors given by:

$$
\mathrm{SSE}=\sum\left(x_{\text {calculated }}-x_{\text {data }}\right)^{2}
$$

\section{Experiment}

Materials used in this experiment were styrene monomer, distilled water, benzoyl peroxide (as initiator), hydroquinone (as inhibitor), and zinc oxide (as suspension agent). Except distilled water, all chemicals were obtained from BDH England (benzoyl peroxide, hydroquinone and $\mathrm{ZnO}$ ) and Merck (styrene monomer). Other supporting chemicals were benzene (as solvent for molecular weight determination), hydrochloric acid and ammonia. Hydrochloric acid was used to dissolve $\mathrm{ZnO}$ to clean the surface of polymer particle product, and ammonia was employed to control the $\mathrm{pH}$ of solution. Analysis of benzoyl peroxide showed that its active content was $25 \%$ (weight).

Styrene monomer was redistilled to purify it from inhibitor (tert. Butyl catechol). Polymerization was conducted in a three neck flask, provided with mechanical stirrer, reflux condenser, thermometer and heated in temperature controlled water bath. In one batch of experiment, $50 \mathrm{~g}$ of styrene, $100 \mathrm{~mL}$ of distilled water, 0.75-3 g of benzoyl peroxide $(\mathrm{BzO})$ and 0.5-2.5 g of zinc oxide powder $(\mathrm{ZnO})$ were employed. The range of reaction temperature was $60-90^{\circ} \mathrm{C}$. Aquadest and $\mathrm{ZnO}$ were charged into the flask, stirred and heated. Meanwhile the mixture was adjusted its $\mathrm{pH}$ to 10 . When the desired temperature was reached, styrene and benzoyl peroxide were charged, while the temperature and stirring speed were kept constant. Sample was taken from the flask every 30 minutes and was analyzed its polymer content by gravimetric method. In this method, fresh sample (from the flash) was added with several drop of $1 \%$ hydroquinone 
solution (to inhibit further polymerization) and then weighed. The sample was dried in vacuum desiccator. In the end of experiment, solid polymer particles was separated from its suspension, washed with dilute $\mathrm{HCl}$ to dissolve $\mathrm{ZnO}$ from the particle surface, and dried. The dried particle sample was measured its diameter by optical microscope. The polymer was determined its (viscosity average) molecular weight by capillary viscometer, using Mark-Houwink-Sakurada equation:

$$
[\eta]=K_{M}\left(M_{v}\right)^{a}
$$

Constants in Eq. (12) for polystyrene solution in benzene is $K_{M}=0.0097 \mathrm{~mL} / \mathrm{g}$ and $a=0.74$ [14].

\section{Results and Discussion}

Based on the experimental data interpretation (i.e., by minimization of SSE), the results are presented in Figs. 1-3 and Table 1. These figures show that calculated conversion $\left(x_{\text {calculated }}\right)$ is close to the data. Solid lines represent the proposed model [Eq. (10)], which is based on $x_{\text {calculated, }}$ while marker points indicate the value of experimental data. This means that the proposed classical model can be used to describe well suspension polymerization of styrene. According to Eq. (10), the conversion of styrene is proporsional to the square root of initial initiator concentration $\left[I_{0}\right]^{0.5}$. Fig. 2 shows that the conversion increases as the initial initiator concentration rises, which is in line with the theory. Fig. 3 also shows that $\mathrm{ZnO}$ (suspension agent) concentration does not affect the conversion, as also confirmed by Eq. (10) that does not contain suspension agent concentration. In this case, for practical purposes, suspension agent concentration is expressed in gram per gram of styrene (monomer + polymer) and initiator concentration is expressed in mol per Liter of styrene.

Table 1 shows the reaction rate constants $K_{p t}$ and $k_{d}$, as well as SSE and relative errors, obtained from the SSE minimization. The proposed model shown by Eq. (10) has relative errors between 2.38\%-10.9\%. Based on the results given in Table 1 , the reaction rate constants $K_{p t}$ and $k_{d}$ can be expressed in the form of Arrhenius equation.

$$
\begin{gathered}
K_{p t}=1.845 \times 10^{15} \exp (-11425 / \mathrm{T})(\mathrm{mol} / \mathrm{L})^{-0.5} \\
k_{d}=6.5 \times 10^{-5} \exp (1585 / \mathrm{T})(\mathrm{min})^{-1}
\end{gathered}
$$

Molecular weight of polystyrene was measured by capillary viscometer. Mark-Houwink-Sakurada

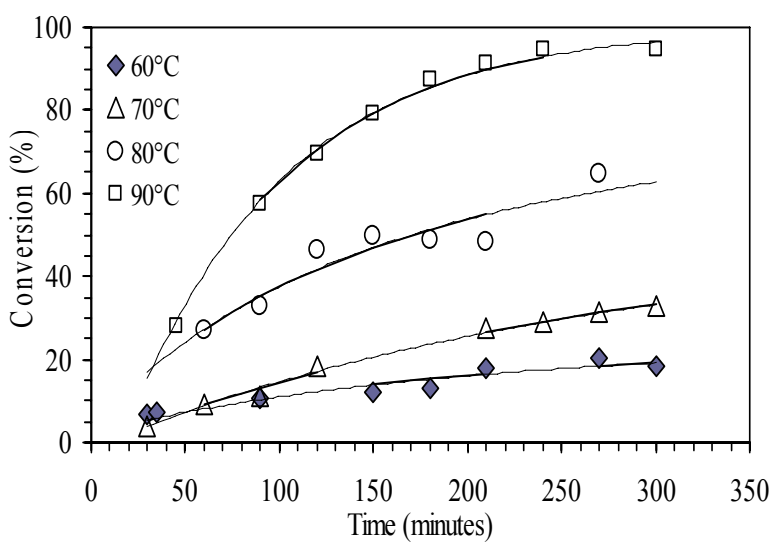

Fig. 1 Conversion of styrene at several reaction temperature.

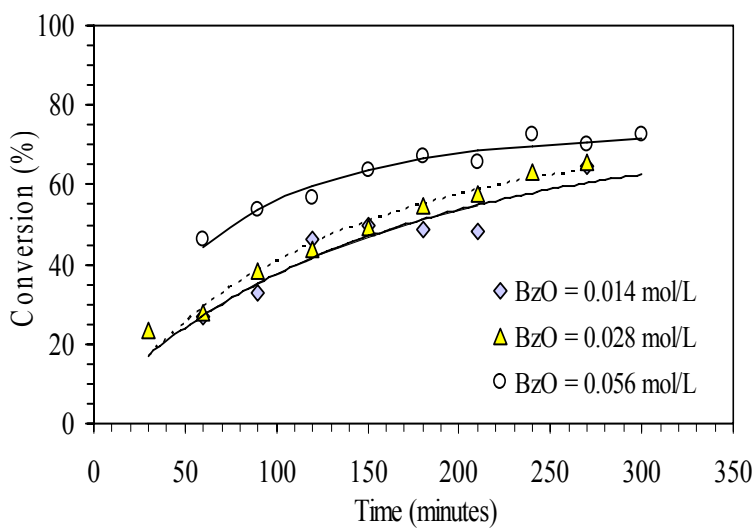

Fig. 2 Effect of benzoyl peroxide (BzO) concentration upon styrene conversion.

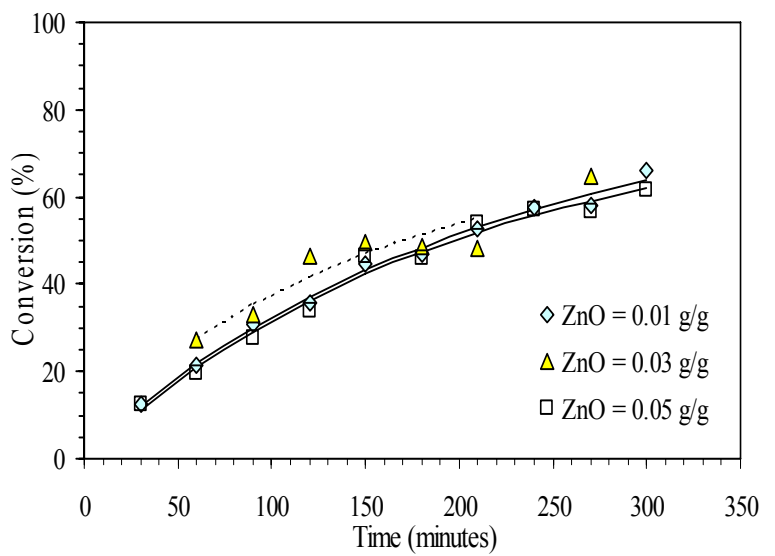

Fig. 3 Effect of suspension agent concentration (ZnO) upon styrene conversion. 
Table 1 The results of SSE minimization on experimental data.

\begin{tabular}{llllllll}
\hline Temperature $\left({ }^{\circ} \mathrm{C}\right)$ & {$\left[I_{0}\right](\mathrm{mol} / \mathrm{L})$} & $\mathrm{ZnO}(\mathrm{g} / \mathrm{g})$ & $K_{p t}(\mathrm{~mol} / \mathrm{L})^{-0.5}$ & $k_{d}(\mathrm{~min})^{-1}$ & $\mathrm{SSE}$ & Error $(\%)$ & Mol weight \\
\hline 60 & 0.014 & 0.03 & 2.34 & 0.00907 & 0.00163 & 10.87 & 673,648 \\
70 & 0.014 & 0.03 & 7.00 & 0.00457 & 0.00084 & 4.38 & 136,884 \\
80 & 0.014 & 0.03 & 12.68 & 0.00693 & 0.01013 & 6.88 & 101,071 \\
90 & 0.014 & 0.03 & 45.10 & 0.00514 & 0.00703 & 4.39 & 343,272 \\
80 & 0.014 & 0.01 & 26.26 & 0.00263 & 0.00187 & 2.38 & 173,278 \\
80 & 0.014 & 0.05 & 18.67 & 0.00385 & 0.00425 & 5.52 & 522,178 \\
80 & 0.028 & 0.03 & 8.56 & 0.00917 & 0.00589 & 5.43 & 305,161 \\
80 & 0.056 & 0.03 & 5.64 & 0.01902 & 0.00305 & 2.42 & 288,050 \\
\hline
\end{tabular}

equation was used to calculate viscosity average molecular weight, provided by Eq. (12). The results is shown in Table 1. The range of molecular weight of polystyrene products is 100,000 to 670,000 . Although the value estimated molecular weight seems scattering, it can be concluded that the increase of temperature $\left(60{ }^{\circ} \mathrm{C}\right.$ to $\left.90{ }^{\circ} \mathrm{C}\right)$ and of the initiator concentration $(0.014$ to $0.056 \mathrm{~mol} / \mathrm{L})$ results in the decrease of

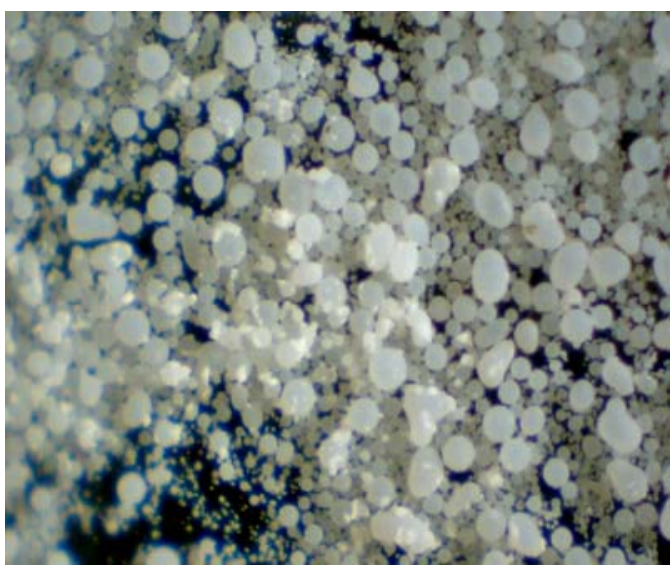

Fig. 4 Sample of polystyrene particles.

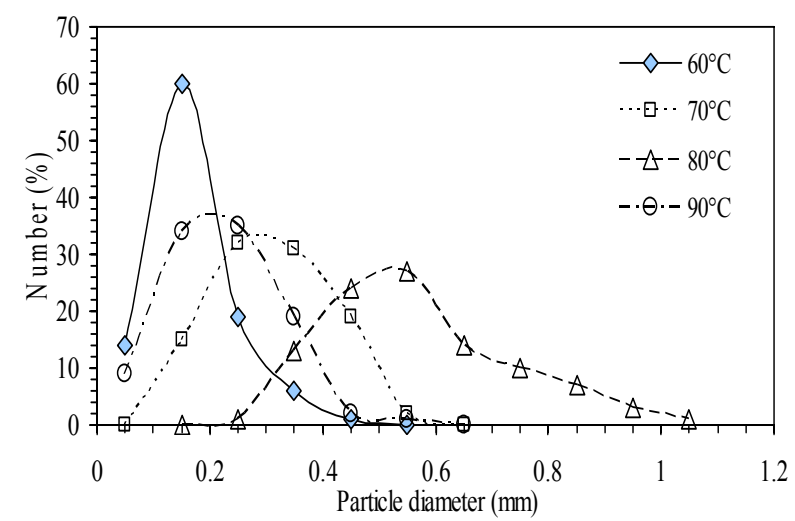

Fig. 5 Particle diameter distribution at several temperature. polystyrene molecular weight. This is in accordance with the basic theory of addition polymerization [13]. Fig. 4 shows example of polystyrene beads in various size. For each experiment, sample of polystyrene particles were measured its diameter by optical microscope. The distribution of particle diameter for several samples is illustrated in Figs. 5 and 6. The particle diameter is generally around $0.1-1 \mathrm{~mm}$.
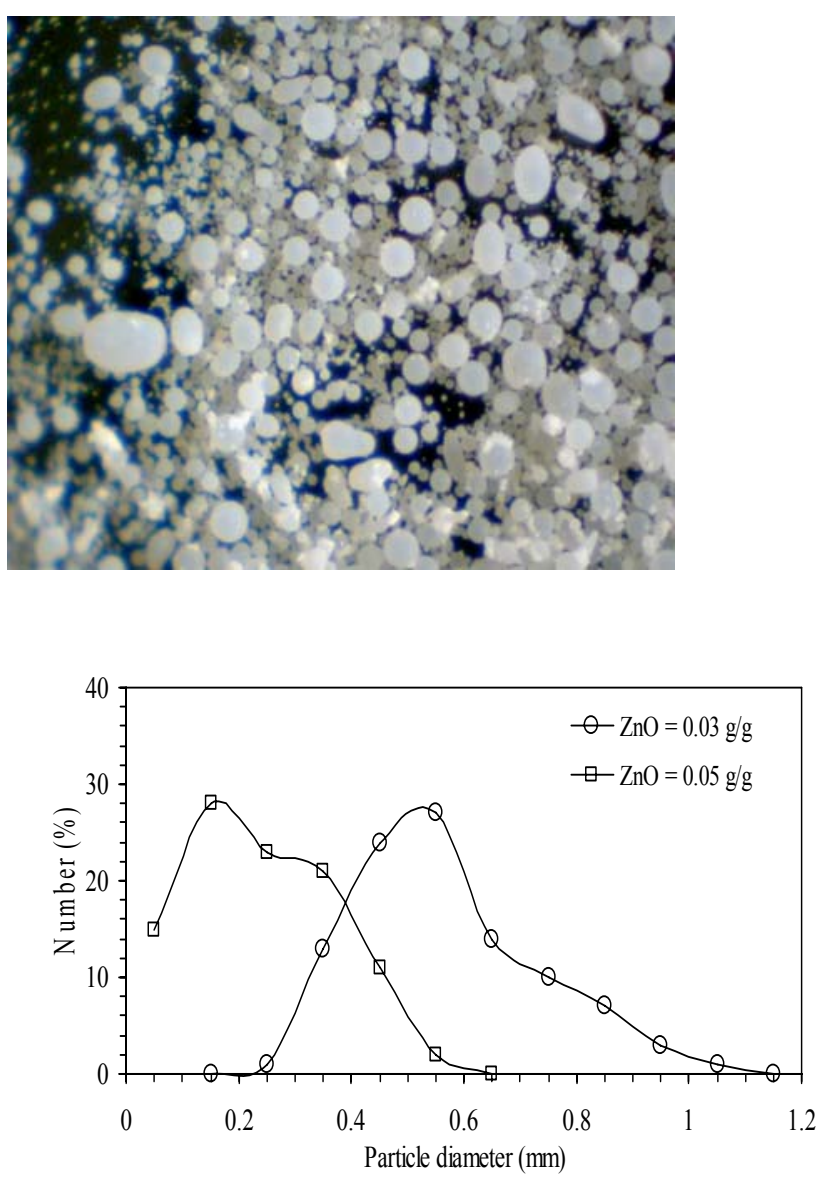

Fig. 6 Particle diameter distribution at two $\mathrm{ZnO}$ concentration. 
The graph shows that reaction temperature and suspension $(\mathrm{ZnO})$ concentration influence the particle diameter. Essentially, particle diameter depends on the diameter of monomer bubbles (dispersed in aqueous phase) in the early stage of polymerization. This bubble diameter is affected by interfacial tension of monomer-water interface (including its condition) and the rotation speed of stirrer. In this experiment, the stirrer speed was maintained to be constant. Lower interfacial tension produces smaller diameter of particle. The existence of $\mathrm{ZnO}$ as suspension agent certainly influences the interfacial tension. As shown in Fig. 6, when $\mathrm{ZnO}$ concentration rises, PS particle diameter tends to decrease, which means that the increase of $\mathrm{ZnO}$ concentration brings the interfacial tension down. However, the temperature rise increases the interfacial tension, as illustrated in Fig. 5 (particle diameter goes up with the increase of temperature).

\section{Conclusions}

The results showed that the proposed reaction rate model is very close to the experimental data, with its relative error being around $2.38 \%-10.9 \%$. The range of overall polymerization reaction rate constants is 2.34-45.1 $(\mathrm{L} / \mathrm{mol})^{0.5}$, which depends on mainly the reaction temperature. The initiator decomposition rate constant was around 0.0051-0.0091 $\mathrm{min}^{-1}$. Suspension agent concentration did not influence the styrene conversion. The diameter of polystyrene particle was around 0.1-1 mm, which was affected by reaction temperature and suspension agent concentration. Viscosity average molecular weight of polystyrene products was between 100,000 to 670,000 .

\section{Acknowledgments}

The authors would like to thank the Chemical Engineering Department, Gadjah Mada University, for providing the laboratory facility to conduct this research.

\section{References}

[1] R. Arshady, A. Ledwith, Suspension polymerisation and its application to the preparation of polymer supports, Reactive Polymers 1 (1983) 159-174.

[2] Y.D. Jo, K.S. Park, J.H. Ahn, S.K. Ihm, Hollow gelular beads of styrene-divinylbenzene copolymer prepared by suspension polymerization, Eur. Polym. J. 32 (8) (1996) 961-912.

[3] O.H. Gonçalves, R.A.F. Machado, P.H.H. Araujo, J.M. Asua, Secondary particle formation in seeded suspension polymerization, Polymer 50 (2009) 375-381.

[4] W.J. Lin, L.T. Biegler, A.M. Jacobson, Modeling and optimization of a seeded suspension polymerization process, Chem. Eng. Sci. 65 (2010) 4350-4362.

[5] L. Lu, C. Jiang, W.X. Fang, P.P. Hui, Y.Z. Ru, Synthesis and characterization of suspension polymerized styrene-divinylbenzene porous microsphere using as slow-release-active carrier, Chinese J. Chem. Eng. 14 (4) (2006) 471-477.

[6] B. Platzer, R.D. Klodt, B. Hamann, K.D. Henkel, The influence of local flow conditions on the particle size distribution in an agitated vessel in the case of suspension polymerisation of styrene, Chem. Eng. Proc. 44 (2005) 1228-1236.

[7] D.R. Lewin, Modelling and control of an industrial PVC suspension polymerization reactor, Computers Chem. Engng. 20 (Suppl. 2) (1996) S865-S870.

[8] D. Maggioris, A. Goulas, A.H. Alexopoulos, E.G. Chatzi, C. Kiparissides, Use of CFD in prediction of particle size distribution in suspension polymer reactors, Computers Chem. Eng. 22 (Suppl. 1) (1998) S315-S322.

[9] E.J. Hukkanen, R.D. Braatz, Measurement of particle size distribution in suspension polymerization using in situ laser backscattering, Sensors and Actuators B 96 (2003) 451-459.

[10] S. Hashim, B.W. Brooks, Drop mixing in suspension polymerization, Chem. Eng. Sci. 57 (2002) 3703-3714.

[11] J.C. Ramirez, J.H. Ordonez, Kinetic aspects of styrene minisuspension polymerization using a mixture PVA-SDS as stabilizer: effect of the time of addition of SDS, Eur. Pol. J. 43 (2007) 3819-3825.

[12] J.C. Ramirez, J.H. Ordonez, V.A. Gonzalez, Kinetics of styrene minisuspension polymerization using a mixture PVA-SDS as stabilizer, Polymer 47 (2006) 3336-3343.

[13] F.W. Billmeyer, Textbook of Polymer Science, 3rd ed., Wiley-Interscience Publication, John Wiley \& Sons, 1984, pp. 56-58.

[14] J. Brandrup, E.H. Immergut, Polymer Handbook, Interscience Publisher, John Wiley and Sons Inc., 1977, pp. V-61. 